\title{
Knowledge work and communication challenges in networked enterprises
}

\author{
Joseph Barjis • Ashish Gupta • Ramesh Sharda
}

Published online: 10 June 2010

(C) The Author(s) 2010. This article is published with open access at Springerlink.com

\begin{abstract}
A modern enterprise is a heavily wired and networked socio-technical system where multiple components play in symphony to yield a competitive position in the ear of digital economy. While the underling communication and interaction systems facilitate knowledge workers to carry out the enterprise mission and furnish service to the society, there are many other aspects that rather have adverse effects on the productivity of an enterprise and interruption of knowledge workers, which pose a serious scientific challenge. In this paper, we briefly discuss certain challenging aspects of knowledge work and communication processes in networked enterprises that require more profound scientific attention in networked enterprises. This paper introduces the problem, identifies some specific research challenges, and then briefly discusses emerging research that addresses some of these challenges.
\end{abstract}

Keywords Communication modeling $\cdot$ Knowledge worker $\cdot$ Knowledge management $\cdot$ Organizational communication · Communication simulation - Email handling $\cdot$ Organizational interruption

\footnotetext{
J. Barjis $(\bowtie)$

Delft University of Technology,

Delft, The Netherlands

e-mail: J.Barjis@TUDelft.NL

\author{
A. Gupta \\ Minnesota State University Moorhead, \\ Moorhead, MN, USA \\ e-mail: Gupta@mnstate.edu \\ R. Sharda \\ Oklahoma State University, \\ Stillwater, OK, USA \\ e-mail: Ramesh.Sharda@okstate.edu
}

\section{Introduction}

Collaboration and interaction in modern enterprises are the only way that the complex activities and processes are carried out. Knowledge work processing plays a pivotal role in the efficient and effective functioning of modern enterprises. Over the past few years, researchers and practitioners have made tremendous progress in developing innovative tools and technologies that have reportedly improved users abilities to capture increasing volumes of information and process more work in short timeframes. On the other hand, new communication technologies, ubiquitous mobile and computing devices are posing greater demands on the knowledge worker's time and attention in a work environment that is now even more technologically and socially wired than ever before.

Despite making significant progress towards streamlining organizational workflow processes with the aid of various technologies, researchers have given little attention to various direct and indirect economic, time and performance implications of having to process so much information in a timely manner. Service organizations such as health care industry, call centers, IS development firms, etc., where knowledge work is the primary output, are particularly impacted by the potential waste of time and effort. What is needed is a systematic study of key organizational communication technologies to develop theories and methods to guide effective and efficient use of these technologies. Analytically, robust solutions need to be developed from several different areas such as conceptual modeling, simulation, social network analysis, and other analytical or empirical approaches to help improving the performance of these technologies as their effects permeate more deeply into work and workers behavior and well being.

In an attempt to compile recent research findings, this special issue put together a few related research papers 
addressing a broad context in which knowledge work and communication of employees are discussed and addressed. In the next section, we briefly discuss a few selected research challenges related to knowledge work and communication among employees in modern enterprises. Afterwards, we summarize the content of selected research papers, which address these selected research challenges to certain extent.

\section{Selected research challenges}

From a myriad of challenges that we see as emerging in the area of knowledge work processing within the networked enterprises, this volume puts together a few representative papers. What follows is a synopsis of the topics. Although there are many other research challenges in modeling communications and networks in organizations, we focus on the topics that introduce the selected papers. A partial list of potential topics for research in this area includes:

1. Knowledge management-models of critical success factors, processes for development of KM systems, diffusion of KM systems within an organization (Alavi and Leidner 2001; Gold et al. 2001).

2. Integration of decision models within business processes, perhaps leading to automated decision systems, e.g., for business process outsourcing (Yang et al. 2007; Gupta et al. 2010).

3. Data mining models to extract useful information from the rapidly growing volumes of enterprise digital data, including email logs and databases (Fayyad et al. 1996).

4. Distributed organizational design - models for prediction of the ideal design and performance, including Collaborative, Participative, and Interactive Modeling (CPI Modeling) (Barjis 2009).

5. Models to better understand organizations stakeholders and their interactions - analysis of linkages within and across collaborative organizations (Bots 2007; Koppenjan and Groenewegen 2005; Deokar et al. 2010)

6. Interruption management - making the best use of an orgaization's most valuable resource-employee (Peinl and Maier 2010; Gupta et al. 2010)

To facilitate decisions about the design of Knowledge Management (KM) initiatives in order to achieve knowledge and business goals, information is required on success factors and barriers when selecting KM measures.

Email communication is standard routine of any knowledge worker, while for majority it might take a significant amount of their work hours. The impact of email processing schedule on the cost of communication in terms of email response time and task completion time definitely poses an interesting research challenge.
For distributed enterprises, it is important to integrate decision models and process management aspects to be able to respond to dynamic workplace environment and behavior.

The complex problem of network infrastructure design requires understanding of individual actor behavior and their interaction with each other.

One more interesting direction emerging from the interaction and relationship of different actors is a complexity of business partner relationship in a networked environment. One such a relationship is the complex web of interrelationship between customers and suppliers in rich informational settings, which requires innovative methods for analysis, e.g., social network analysis.

Another quite data intensive aspect of human activity is processing of huge amount of daily data (terabytes per day) in business industry, which without modern technology requires tremendous human resources.

Models, as a tool in decision making, play enormous role in complex and data rich environments, especially with uncertainties and forecasting situation.

In the following section, we summarize selected research papers, in which some of the above identified research challenges are discussed and addressed.

\section{Paper summaries}

In the paper "SimKnowledge-Analyzing Impact of Knowledge Management Measures on Team Organizations with Multi Agent-Based Simulation" Peinl and Maier (2010) present a simulation model for analyzing the effects of knowledge management measures within organizations. This paper focuses on modeling knowledge work within one organization. Multi agent-based simulation (MABS) is proposed to explore possible effects of KM measures on dependent variables such as sharing of knowledge in organizations or business performance. For a MABS, the concept of knowledge sharing, influencing factors and their impact on business and knowledge goals is represented in a conceptual model based on various multi-disciplinary literature. The simulation model, which is based upon the knowledge sharing model and domain model, is implemented in a MABS tool. This tool is employed for a number of experiments investigating and contrasting results with/ without KM measures. Therefore, the relationship of a number of factors is investigated. Two simulation studies are conducted including one human- (skill management system) and one document-oriented KM measure (documentation of learning experiences). The study results provide detailed explanations on various hypothesis related to the KM measures. For example, the authors found that the use of a skill management system do not automatically result in quicker completion of work packages, but its success largely 
depends on the strategy for assigning work packages to workers, and that, documentation of experiences is more effective in the simulated scenarios than skill management.

In the paper "You've Got Email! Does it Really Matter to Process Emails Now or Later?" Gupta et al. (2010) describe the result of a simulation study that simulates knowledge workers and their email processing behavior. Based on the effects described in literature that processing of emails interrupts the primary work tasks, it is analyzed whether different email processing strategies can reduce interruption lags and therefore increase efficiency and reduce overall working hours. The authors aim to test several different email processing policies to understand how it affects email response time, task completion time, efficiency, and interruptions. They compare policies of checking email continuously, during specific blocks of time spread evenly throughout the day, and checking email during specific blocks of time during peak email load. The authors find that a more structured and non-continuous email access is the optimal strategy. At the same time, checking email too infrequently fails to maintain an adequate balance between task completion time and email response time. The hypothesis is whether certain email policies yield better results regarding the dependent variables. The results show that processing emails twice or four-times a day is superior to checking emails continuously or only once a day. The research methodology is based on a simulation study. The proposed simulation model tests a variety of different strategies, email types, and arrival rates, and processing times. They then statistically analyze the results of these tests to identify the best strategies under specific circumstances.

In the paper titled "Decision-enabled Dynamic Process Management for Networked Enterprises" Deokar et al. (2010), bring together the dynamic process management and distributed model management by proposing a framework that integrates process management and decision models. The proposed framework overcomes three major challenges that are often experienced in any decentralized networked environment: (1) the lack of integration between the decision models and process aspects in current settings; (2) the need to respond to dynamic business process changes; and (3) Managing processes in distributed settings. The study the need for such a framework in three different scenarios: human resource management, supply chain management and decision support for clinical environments. Finally, a serviceoriented architecture combined with advances from the semantic web field for model management support within business processes is also proposed.

In the paper titled "Modeling the Dynamic Interactions of Agents in the Provision of Network Infrastructure" DeMaagd and Bauer (2010) address and analyze a difficult problem of network infrastructure design using genetic programming (GP) by modeling the interactions between three groups (platform providers, application providers, and consumers) of self-interested, utility-maximizing agents. The decision making of each group of agent is guided by a given set of rules. The study examines the impacts of the co-evolving strategies of each group of agents and finds a solution that is mutually beneficial to all agents. The results indicate that the increase in the number of telecommunication platform providers deliver is beneficial for application providers and the discriminatory pricing strategies are good for application providers but not for the telecommunications companies.

In the paper "Strategic Choices of Inter-organizational Information Systems: A Network Perspective" $\mathrm{Hu}$ et al. (2010) investigate the structural characteristics of interorganizational information systems by emphasizing the value of interconnected business systems. The authors analyze customer-supplier relationships in five diverse industries (IT, retail, service, healthcare, and finance) in order to gain insights on strategies for choosing inter-organizational information systems (IOIS) in a networked environment. Social network analysis (SNA) is used as the primary methodology. Related analysis techniques such as clustering and visualization are also used in this regard. Using a set of analysis, namely, descriptive statistics, SNA Centrality Measures, SNA Visualization Analysis and Cluster analysis, they classify the network topologies into customer-centric networks, suppliercentric networks and balanced networks. In customer-centric networks, a small number of customer firms are connected to many suppliers and this gives customers a positional advantage while the opposite is true for supplier-centric networks. However, in balanced networks, neither customer nor supplier firms have positional advantage. Based on the empirical findings, the authors make suggestions regarding the strategic choice of network types.

In the paper "The impact of RFID technology on warehouse process innovation: A pilot project in the TPL industry" Fosso Wamba and Chatfield (2010) discuss the enabling role of RFID technology in effecting warehouse process optimization. This paper presents the preliminary results of a pilot project of a longitudinal case study of a third-party logistics (TPL) supply chain. Using the value chain model and business process modeling techniques, this study contributes to the field of business process improvement through new technologies such as RFID. More specifically, the improvement of merging the existing picking and shipping processes through RFID is described. The implementation of this innovative technology helps to release human resources, increase accuracy, and automate data processing. In turn, it helps to cut costs in the outbound logistics part of the supply chain. However, the findings of this study reveal the initial costs of RFID technology implementation are the key inhibiting factor of 
RFID widespread adoption and usage among suppliers. Overall, this paper uses a process view to analyze the benefits of RFID adoption. It does this by studying a Canadian logistics firm and its benefits even if other supply chain partners do not adopt RFID. The authors find that the RFID results in a $17 \%$ time savings for the logistics firm. An interesting point in this paper is that it stands in contrast to some analysis on the benefits of RFID that assume that entire supply chain magically decides to all adopt RFID and everyone receives the optimal benefits.

Nsakanda (2010), in his paper "An Aggregate InventoryBased Model for Predicting Redemption and Liability in Loyalty Reward Programs Industry" proposes an aggregate model for predicting redemption and liability in loyalty reward programs (LRPs), and provides a brief illustration of the proposed approach. They also implement the model and verify it with a real-life example. The proposed approach and model procedure serve as a useful tool for forecasting the redemption, which is helpful for managers to manage their budgets and develop their promotion plans. As opposed to existing models in this domain, the proposed model considers LRP as a dynamic system in which members or customers are divided into various tiers. Thus, it takes into consideration customers' characteristics and changes in their behavior over time. When the forecasts generated by the model are compared to the actual results, there is rather a small margin of forecasting error, which is promising, as the researchers claim.

As the above summaries show, some of the goals (research challenges) we set have been realized, but other research challenges in modeling communication issues remain open. It is hoped that the open issues will stimulate further research into this promising and relevant research direction.

\begin{abstract}
Acknowledgement For the success and appearance of this special issue, we would like to cordially the journal editors in chief Professors R. Ramesh and H. Raghav Rao for their approval of this special issue and support throughout the process, and the entire executive and production team working behind the scene. Next, we would like to thank the reviewers who dedicated their time and efforts to help that relevant papers are selected and needed improvements are made before their publication. Finally, our deepest appreciations go to the authors for their excellent contribution and diligent work as their papers made rounds of reviews.
\end{abstract}

Open Access This article is distributed under the terms of the Creative Commons Attribution Noncommercial License which permits any noncommercial use, distribution, and reproduction in any medium, provided the original author(s) and source are credited.

\section{References}

Alavi, M., \& Leidner, D. E. (2001). Review: knowledge management and knowledge management systems: Conceptual foundations and research issues. MIS Quarterly: Management Information Systems, 25(1), 107-136.
Barjis, J. (2009). Collaborative, participative and interactive enterprise modeling. In J. Filipe \& J. Cordeiro (Eds.), Enterprise information systems. Lecture notes in business information processing, volume 24. Berlin: Springer-Verlag.

Bots, P. W. G. (2007). Design in socio-technical system development: three angles in a common framework. Journal of Design Research, 5(3), 382-396. ISSN 1748-3050.

DeMaagd, K. \& Bauer, J. (2010). Modeling the Dynamic Interactions of Agents in the Provision of Network Infrastructure. Information System Frontiers, 13(5), 669-680.

Deokar, A. V., El-Gayar, O. F., \& Aljafari, R. (2010). Decisionenabled Dynamic Process Management for Networked Enterprises. Information System Frontiers, 13(5), 655-668.

Fayyad, U. M., Piatetsky-Shapiro, G., \& Smyth, P. (1996). From data mining to knowledge discovery: an overview. In U. M. Fayyad, G. Piatetsky-Shapiro, P. Smyth, \& R. Uthurusamy (Eds.), Advances in knowledge discovery and data mining (pp. 1-34). Menlo Park: American Association for Artificial Intelligence.

Fosso Wamba, S. \& Chatfield, A. T. (2010). The impact of RFID technology on warehouse process innovation: A pilot project in the TPL industry. Information System Frontiers, 13(5), 693-706.

Gold, A. H., Malhotra, A., \& Segars, A. H. (2001). Knowledge management: an organizational capabilities perspective. Journal of Management Information Systems, 18(1), 185-214.

Gupta, A., Sharda, R. \& Greve, R.A. (2010). You've got email! Does it really matter to process emails now or later? Information System Frontiers, 13(5), 637-653.

Hu, D., Zhao, X. \& Zhao, J. L. (2010). Strategic choices of interorganizational information systems: a network perspective. Information System Frontiers, 13(5), 681-692.

Koppenjan, J., \& Groenewegen, J. (2005). Institutional design for complex technological systems. International Journal of Technology, Policy and Management, 5(3), 240-257.

Nsakanda, A. (2010). An aggregate inventory-based model for predicting redemption and liability in loyalty reward programs industry. Information System Frontiers, 13(5), 707-719.

Peinl, R. \& Maier, R. (2010). SimKnowledge - analyzing impact of knowledge management measures on team organizations with multi agent-based simulation. Information System Frontiers, 13(5), 621-636.

Yang, D.-H., Kim, S., Nam, C., \& Min, J.-W. (2007). Developing a decision model for business process outsourcing. Computers and Operations Research, 34(12), 3769-3778.

Joseph Barjis is an Associate Professor of Systems and Simulation at Delft University of Technology. His research interests are focused on business process modelling and simulation, enterprise modelling and simulation, healthcare processes modelling and simulation, information systems design, system analysis and design, collaborative, participative, and interactive modelling. He is the founder of the Special Interest Group on Modelling and Simulation (SIGMAS) of the Association for Information Systems (http://www.AIS-SIGMAS.org/) and the International Workshop on Enterprise \& Organizational Modelling and Simulation (http://www.EOMAS.org/); he serves as a member of Program Committee and Editorial Board in several international conferences and journals (see more: http://www.JosephBarjis.com).

Ashish Gupta is Assistant Professor in School of Business at Minnesota State University Moorhead. Ashish has a PhD in Management Science and Information Systems from Oklahoma State University. His research interests are in the areas of information overload, email management, instant messaging, interruptions, Healthcare, simulation modeling. His recent articles appeared in journals such as Communications of AIS, Information Systems Frontiers, Annals of 
Information Systems, etc. He is serving as guest editor of the Special issue of Decision Support Systems on 'Modeling for Better Healthcare'. He serves on the editorial board of IJDSST and IJITSA.

Ramesh Sharda is Director of the Institute for Research in Information Systems (IRIS), ConocoPhillips Chair of Management of Technology, and a Regents Professor of Management Science and Information Systems in the Spears School of Business at Oklahoma State University. His research has been published in major journals in management science and information systems including Management Science, Information Systems Research, Decision Support Systems, Interfaces, INFORMS Journal on Computing, Computers and Operations Research, and many others. His co-authored text book (Decision Support and Business Intelligence Systems by Turban/Sharda/Delen, 9th edition, Prentice Hall) has just been released. He serves on the editorial boards of journals such as the INFORMS Journal on Computing, Decision Support Systems, Information Systems Frontiers, and OR/MS Today. Ramesh is also a cofounder of a company that produces virtual trade fairs, iTradeFair.com. 